\title{
Radical embodiment in two directions
}

\author{
Edward Baggs $^{1}$ (D) Anthony Chemero ${ }^{2}$ \\ Received: 28 May 2018 / Accepted: 12 November 2018 / Published online: 20 November 2018 \\ (C) The Author(s) 2018
}

\begin{abstract}
Radical embodied cognitive science is split into two camps: the ecological approach and the enactive approach. We propose that these two approaches can be brought together into a productive synthesis. The key is to recognize that the two approaches are pursuing different but complementary types of explanation. Both approaches seek to explain behavior in terms of the animal-environment relation, but they start at opposite ends. Ecological psychologists pursue an ontological strategy. They begin by describing the habitat of the species, and use this to explain how action possibilities are constrained for individual actors. Enactivists, meanwhile, pursue an epistemic strategy: start by characterizing the exploratory, self-regulating behavior of the individual organism, and use this to understand how that organism brings forth its animal-specific umwelt. Both types of explanation are necessary: the ontological strategy explains how structure in the environment constrains how the world can appear to an individual, while the epistemic strategy explains how the world can appear differently to different members of the same species, relative to their skills, abilities, and histories. Making the distinction between species habitat and animal-specific umwelt allows us to understand the environment in realist terms while acknowledging that individual living organisms are phenomenal beings.
\end{abstract}

Keywords Radical embodied cognitive science - Ecological psychology · Enactivism · Affordances · Information · Umwelt

There are currently two main flavors of radical (i.e., nonrepresentational) embodied cognitive science. On the one hand, there is ecological psychology, whose proponents draw their influence primarily from the work of James Gibson; on the other hand there is enactivism, whose proponents are influenced primarily by the work of Humberto

$凶$ Edward Baggs

ed.baggs@gmail.com

1 Bartlett School of Architecture, University College London, 22 Gordon St. Bloomsbury, London WC1H 0QB, UK

2 Center for Cognition, Action, and Perception, University of Cincinnati, Cincinnati, USA 
Maturana and Francisco Varela (1987). Both ecological psychology and enactivism reject the idea that cognition is defined by the computational manipulation of mental representations; both also focus on self-organization and nonlinear dynamical explanation. They differ in emphasis, however. Ecological psychology focuses on the nature of the environment that animals perceive and act in; enactivism focuses on the organism as an agent. Combining the two would seem to provide a complete picture of cognition: an enactive story of agency, and an ecological story of the environment to which the agent is coupled. Indeed, several radical embodied cognitive scientists, including us, have called for just such a unification (Chemero 2009; McGann 2014; Baggs 2018). Unfortunately, there seems to be a major philosophical barrier to such a unification: historically, the two traditions have developed from seemingly opposing starting assumptions. Ecological psychologists have traditionally asserted a commitment to realism, while enactivism was initially developed within a constructivist, and therefore anti-realist, framework. Early enactivist writings, indeed, can be more naturally read as advocating a form of idealism rather than realism.

The deep contrast between the two approaches is well illustrated in a remark by Varela, Thompson, and Rosch in their classic The Embodied Mind (1991). The authors specifically distance their approach from ecological psychology because the latter assumes that animals live in a "pre-given" world.

Thus the resulting research strategies are also fundamentally different: Gibsonians treat perception in largely optical (albeit ecological) terms and so attempt to build up the theory of perception almost entirely from the environment. Our approach, however, proceeds by specifying the sensorimotor patterns that enable action to be perceptually guided, and so we build up the theory of perception from the structural coupling of the animal. (204)

Around the same time, ecological psychologists critiqued the theory of autopoiesis that served as the foundation for Varela et al's enactivist views, calling it overtly idealist and offering a realist alternative, based in thermodynamics, called autocatakinesis (Swenson and Turvey 1991). Swenson (1992), for example, is extremely harsh in his criticism: “... the whole concept of autopoiesis is contrived at its foundations where it is miraculously decoupled from the physical world to promulgate a solipsistic epistemology with abhorrent social consequences" (207). As is often the case, both these characterizations present straw versions of the view they critique.

We believe that these decades-old texts set up an unfortunate paucity of contact between ecological psychology and enactivism. This is primarily an educational phenomenon: ecological psychologists read Swenson and Turvey in graduate school and think that enactivists are idealists who neglect the world; enactivists read Varela et al. in graduate school and think that ecological psychologists are realists that neglect experience. Our goal in this paper is to try to overcome the ontological differences between ecological psychology and enactivism. We will not do so by offering arguments that ecological psychologists should adopt idealism, or that enactivists should commit to realism. In our view, the realism v. idealism debate is not useful, and committing to either position would be counterproductive. Instead, we will describe a view of the relation between animals and environments that fits both enactivism and ecological psychology, and can be interpreted as tending toward either realism or idealism. The 
way we will do this is by revising a key distinction that Gibson makes in The Ecological Approach to Visual Perception (1979), that between the physical world and the ecological environment. Gibson's way of making this distinction, we will argue, has sown substantial confusion and controversy among ecological psychologists, especially over key ecological notions such as affordances and information. Revising this distinction enables us to alleviate these confusions and controversies within ecological psychology and to show how the enactivist and ecological approaches fit together. ${ }^{1}$

\section{James Gibson's theory of affordances}

James Gibson's ecological approach was developed from a confounding collection of influences: like nearly every American psychologist in the middle of the 20th century, Gibson considered himself a behaviorist; he also considered himself a Jamesian radical empiricist; he worked closely with the Gestalt psychologist Kurt Koffka; he was a careful reader of phenomenology, especially that of Merleau-Ponty (see Gibson 1967; Reed 1988; Käufer and Chemero 2015). All of these influences are baked into Gibson's The Ecological Approach to Visual Perception (1979), which partly explains why, despite the plainness of its prose, the text is sometimes quite difficult to understand. We can see the impact of each of these influences in Gibson's writings on affordances. The most frequently cited example of this is in Gibson's definition of his neologism 'affordances', or opportunities for behavior, which Gibson claims are the main things that animals perceive. "The affordances of the environment are what it offers the animal, what it provides or furnishes, either for good or ill" (1979, 127). A few pages later, Gibson writes, much less straightforwardly:

An important fact about the affordances of the environment is that they are in a sense objective, real, and physical, unlike values and meanings, which are often supposed to be subjective, phenomenal, and mental. But, actually, an affordance is neither an objective property nor a subjective property; or it is both if you like. An affordance cuts across the dichotomy of subjective-objective and helps us to understand its inadequacy. It is equally a fact of the environment and a fact of behavior. It is both physical and psychical, yet neither. $(1979,129)$

We can see each of the influences mentioned above in Gibson's theory of affordances.

First, the idea that we primarily experience affordances echoes Merleau-Ponty's phenomenology, on which Gibson taught a seminar in the early 1970s (Käufer and Chemero 2015). For Merleau-Ponty (1945/2012), a human subject is not defined, as Descartes had it, as an "I think", but rather as an "I can". The world we experience, for Merleau-Ponty, is a field of possibilities for skilled action. Second, the denial of the dichotomy between subjectivity and objectivity in the theory of affordances echoes

\footnotetext{
1 We will principally be concerned here with enactivism as developed first by Varela, Thompson, and Rosch (1991), and subsequently by Thompson (2007) and Di Paolo et al. (2017). This tradition is unified by an emphasis on the actor's phenomenology and agency. Our focus is not intended in prejudice against the other approaches going under the name of enactivism. See Ward et al. (2017) for a discussion of the relations between these various enactivist traditions.
} 
both Merleau-Ponty and the later work of William James. Merleau-Ponty wrote that "The world, inasmuch as it harbors living beings, ceases to be a material plenum consisting of juxtaposed parts; it opens up as the place where behavior appears" (1942/1963). James, in his late writings on radical empiricism, defended what was later called neutral monism. Neutral monism is a rejection of mind-body dualism according to which there is just one realm, but it is neither mental nor material. James called this realm 'pure experience'. One regularly raised concern about neutral monism is that it is in fact not neutral: James' pure experience and Merleau-Ponty's place where behavior appears both seem to be mental, and the denial of dualism becomes a form of idealist monism (e.g., O'Shea 2018). This of course would not be acceptable to Gibson, a naturalist and behaviorist. The molar behaviorism of E.B. Holt, Gibson's dissertation advisor, was an attempt to make Jamesian radical empiricism into a respectable (i.e., behaviorist) psychological theory. Finally, Gibson explicitly cites the Gestalt concept of 'Aufforderungscharakter', usually translated as 'valence' or 'demand character', as inspiration in his chapter on affordances. The glass of wine is not experienced as merely being tulip-shaped and wet, but also as calling out to be drunk. The difference between affordances and valences, Gibson said, is that the Gestalt theorists assumed that valences were phenomenal objects. The glass of wine is a physical object, but its valence is not. Gibson rejects this dualism in his theory of affordances. Affordances, Gibson insists, are not phenomenal, but real features of the world; they exist even when no animal is perceiving them. The affordances of the glass of wine continue to exist when there are no humans there looking for a drink.

The key to Gibson's theory of affordances, and the most radical part of his theory of perception, is the distinction Gibson makes between the physical world and the environment of animals. The physical world exists at all spatial and temporal scales, from nanoseconds and nanometers to millennia and galaxies. The environment of animals is limited to the middle scale. For humans, the spatial scale of the environment is from millimeters to kilometers; the temporal scale is from hundreds of milliseconds to decades. Space in the physical world is understood geometrically. Space in the environment is understood in terms of locomotion and perception. The environment consists of points of observation, places where an animal can put its sensory organs, and paths of locomotion connecting them. The environment of animals is not perceived in terms of time, but in terms of events: of things transforming or persisting under movement. Physical time, as measured in seconds, is an abstraction (Gibson 1975). (The key innovation of clocks is to instantiate this abstract system of time and render it perceivable as movements of the clock hands; see Smith 1988.) The physical world is made of whatever invisible particles physicists talk about; the environment is made of the middlesized entities near the surface of the earth. Most crucially, the physical world is inherently meaningless, but the environment is not; the environment contains affordances.

In addition to containing affordances, the environment contains information about affordances. The laws of optics make it such that the light reflected from things in the environment is structured by the properties of those things. This lawful relationship between light and what it reflects from makes it the case that light contains information. Gibson's argument that light (and chemical gradients and vibrations in the air and...) contains information about affordances is long and detailed, and we will come back to it in Sect. 3. For now, as an example, we can point out that the light reflected to any 
point of observation will be lawfully related to both (1) the height of the tree branch off which the light reflected and (2) the height of the point of observation. This means that the light can carry information about whether the tree branch affords reaching, grabbing, climbing, etc. for the animal whose eyes are at that point of observation, and that information will be there at the point of observation, waiting for the animal to show up and put its eyes there.

This is the key point: the environment is not a separate mental realm; it is just a subset of the physical world, considered from the vantage point of an animal. Because the environment contains affordances, there is no need for the animal to construct meaningful experience by building and manipulating representations in some phenomenal realm, or even in the brain. In fact, meaningful experience doesn't happen inside the animal: an animal using information to learn about the affordances of the environment is having meaningful experience. This satisfies Gibson's dual goals of maintaining neutral monism, but not having it slide into idealism. The one realm which contains both meaning and matter is the physical world. The sub-atomic particles that make up the physical world do not, in and of themselves contain meaning, but when looked at the from the point of view of a behaving animal, a portion of the physical world is also the meaningful environment. Gibson was, as he often put it, a realist about affordances. This placement of affordances, of meaning, in the environment, which is a subset of the physical world, is a dramatic departure both from the Gestalt distinction between phenomenal and material realms and the contemporary cognitivist monism which assumes that meaning is built up in the brain. Gibson's realism about meaning also enables what Edward Reed (1996) has called the 'fundamental thesis of ecological psychology': affordances, and only affordances, guide natural selection. Because there are both affordances and information about affordances in the habitat, species can evolve to take advantage of those affordances.

What Gibson did with his theory of affordances is to develop a novel ontological position, a naturalist neutral monism that in no way slides toward idealism in which there are only mental entities. Indeed, as we saw from the quotation by Varela et al. above, some readers have taken Gibson to have posited a form of physicalist monism, which eliminates mental entities. He also explains how meaning can be a feature of the natural world and how it can guide evolution by natural selection. The key to all of this is Gibson's distinction between the meaningful environment of animals and the meaningless physical world. In the remainder of this paper, we will argue that the distinction between the world and the environment cannot carry all of this burden alone. (In what follows, we are building on arguments we have developed elsewhere; see Baggs and Chemero, to appear.)

\section{The environment of the species and the environment of the individual}

Gibson makes his distinction between the environment and the physical world on the first page of the first chapter of his final book. Immediately afterwards, he points out a potential problem with this distinction. In talking of the environment as surrounding an animal, it remains ambiguous whether what is being referred to is a specific individual 
animal, or an ideal animal that represents a typical member of that species. Gibson writes:

The environment consists of the surroundings of animals. Let us observe that in one sense the surroundings of a single animal are the same as the surroundings of all animals but that in another sense the surroundings of a single animal are different from those of any other animal. These two senses of the term can be troublesome and may cause confusion. The apparent contradiction can be resolved, but let us defer the problem until later. (The solution lies in the fact that animals are mobile.) $(1979,7)$

Gibson's solution to this problem, as the remark in parentheses indicates, was to assert that, because all members of a species can in principle occupy the same set of points of observation relative to the surfaces around them, it is in fact the case that all members of the species share a single environment: the environment for any given individual is the same as the environment for any other member of that species (Gibson 1979, 43).

There is certainly something appealing about this argument. For one thing, it appears to offer a bulwark against solipsistic views of perception: if we all see the same environment, then all disagreements between people can in principle be resolved simply by referring to the external facts (Costall 1995). As Gibson put it, "The basis for agreement among men exists in the available stimulus information" (1966, 321).

Nevertheless, the solution fails. It fails because it does not acknowledge the role of learning or the capacities of the perceiver's body in shaping the way the world appears to the individual. There remains a sense in which the world can appear differently to two different people, even if we take turns positioning ourselves at the exact same positions relative to the surrounding surfaces. Gibson's solution fails to account for the fact that a newspaper that is written in a particular language affords reading only for a certain subset of the world's population, namely the set of people that are literate in that language; or, again, it fails to account for the fact that a set of stairs affords climbing only for a subset of fit, able-bodied people.

For these reasons, we have argued (Baggs and Chemero, to appear) that it is necessary to subdivide what Gibson referred to as the environment. We need to make a finer distinction between, (1) the environment as a set of resources for a typical, or ideal, member of a species, which we call the habitat, and (2) the environment as the meaningful, lived surroundings of a given individual, which we call the umwelt (Von Uexküll 1934/1992). We offer this as a friendly amendment to Gibson's distinction.

It is important to note that in making this further distinction we are not advocating a retreat to solipsism. The umwelt is not a private, mental copy of the habitat. It is the habitat considered from the point of view of a particular living animal. Similarly the habitat is not distinct from the physical world: it is a subset of the physical world considered relative to a typical member of a species. When an animal performs an action, this typically has consequences in the umwelt, the habitat, and the physical world. See Box 1 for a detailed example.

Making this three-way distinction-between physical world, habitat, and umwelt-allows us to resolve several outstanding controversies within ecological psychology. 
Box 1 Physical world, habitat, umwelt, and the Panama Canal

Our claim is that it is useful to distinguish between three different senses of environment. We are aware that it may remain unclear in what way these three senses relate to one another. We here offer an example to try to clarify matters. The key is to recognize that these are three different ways of describing the same thing, namely, the layout of the world, and changes to that layout. We use the Panama Canal as our example

When construction of the Panama Canal was completed, the project had quite literally changed the structure of the physical world. Where previously the North and South American landmasses had been connected at the ground level, they were now separated by a continuous waterway

In terms of the habitat, this change had meaningful consequences for the possible behaviors that humans could now engage in. The habitat is the physical world described relative to a potential actor, or set of actors. Whereas ship crews previously had to navigate thousands of kilometers around South America, it was now possible to take a much quicker shortcut through the canal. It is here appropriate to talk about the canal's function: to speed up shipping between the Atlantic and Pacific oceans

The umwelt is the habitat described from the perspective of a given individual actor, a particular human in this case. The Panama Canal enters directly into the behavior of relatively few humans. Most humans will never actually see the Panama Canal, although we expect any educated fellow human to be aware of its existence. The point is that from the perspective of any given human, the Panama Canal is now something that is just there: it is part of the permanent structure of our world. We do not have to rebuild the Panama Canal every time we think about it. It is simply there as a structure we might direct our behavior towards. It may enter into our behavioral dealings in a particular way depending on what we end up doing with our lives: perhaps we might find ourselves planning a cruise vacation in Central America, or perhaps running a shipping container logistics company. In describing the canal as part of an individual's umwelt, the canal's function as a shipping corridor is already presupposed - the function is already built into the fabric of the socio-material world. The umwelt is instead to be understood relative to an individual actor's intentions and agency

Of course, it is not just major feats of engineering that can be described in terms of the three senses of environment. Any event that changes the structure of the physical world can be described in all three ways. When a beaver gnaws down a tree or a fish lays its eggs under a rock, this re-arranges the layout of the world in a way that has consequences in all three senses of environment, relative to certain animals and their purposes

\section{Clarifying confusions and controversies}

A number of tensions have arisen among ecological psychologists over how best to interpret several of the concepts that were central to Gibson's ecological approach. We here focus on two of these: the concept of affordances, and the concept of ecological information. (This is in part a summary of discussion in Baggs and Chemero, to appear).

\subsection{Affordances}

As outlined in Sect. 1, the affordance concept is a radical attempt to develop a novel ontology for psychology, one that unifies insights from several sources, including phenomenology, Gestalt psychology, and Jamesian radical empiricism. Since Gibson outlined the concept, however, a tension has arisen over exactly what the ontologi- 
cal status of affordances should be. Specifically: should we think of affordances as dispositional properties, relational properties, or something else?

The former position, that affordances are dispositions, is suggested by Gibson's initial definition of affordances as what the environment "offers the animal" (Gibson $1979,127)$. On this view, affordances are conceived as enduring properties of objects and surfaces that exist in the environment of all members of a species (Turvey 1992). A consequence of this view is that it requires that animals possess a reciprocal dispositional property, an 'effectivity', in order for the affordance to be actualized. A tree branch affords perching to a bird with the appropriate perching effectors, and under the appropriate conditions. The affordance is actualized whenever an animal possessing the appropriate effectivity comes along. An important reason for conceiving of affordances as 'out there' properties, in this way, is that it allows us to talk about affordances as providing evolutionary selection pressure on a species: the affordances exist irrespective of the survival of any given individual, and provide persisting structure across generations (Reed 1996). It should be noted that there is a difficulty created by making affordances and effectivities into simple dispositional properties: dispositions are actualized whenever the appropriate conditions are met. Thus whenever a glass of wine, which is disposed to be drunk, is co-present with the appropriate effectivities (for reaching, grasping, sipping, etc.), drinking should occur. Yet somehow most of us, most of the time, are sober, despite the co-presence of our drinking effectivities and the affordances of wine.

An alternative view conceives of affordances as relational properties that arise, or can potentially arise, in the encounter of a given animal with some structure in its surroundings (Chemero 2003, 2009; Rietveld and Kiverstein 2014). On this view, affordances are defined relative to the skills or abilities that the organism possesses. A major advantage of this way of thinking is that it allows us to account for differences in behavior between members of the same species. An airplane flight control panel affords something to a trained pilot that it does not afford to a child. The stairs on the railway platform afford climbing to some individuals but not others. This view is more compatible with Gibson's second definition of affordances as "neither an objective property nor a subjective property" (Gibson 1979, 129).

As is clear, these two views of affordances have different strengths and weaknesses. The affordances-as-dispositions view allows affordances to play a role in evolution, but leaves obscure the conditions under which a given affordance is actualized. The affordances-as-relations view, meanwhile, allows us to accommodate learning and bodily capacities into the perceptual process, but at the risk of once more rendering perception relativistic and solipsistic: if we only see affordances relative to our own skills, are we not again confined to a private inner world?

It is worth repeating that the tension here arises out of something that Gibson long struggled with: his attempt to reconcile insights from Gestalt psychology with his view, alluded to above, that any morally acceptable psychology must be grounded in a realist understanding of the world in which we all have access to the same worldly structures (Heft 2017). As Gibson acknowledges, and as we mentioned above, the affordance concept is indebted to earlier Gestalt notions of demand character and valence, owing to Koffka and Lewin. For the Gestalt psychologists, these concepts relied on a distinction between a phenomenal world and a geographical or physical world. A postbox exists 
as a structure in the physical world, and in addition there is a phenomenal postbox that invites behavior from someone who has a letter to mail. Gibson rejected this (1979, 139), "For Koffka, it was the phenomenal postbox that invited letter-mailing, not the physical postbox. But this duality is pernicious. I prefer to say that the real postbox (the only one) affords letter-mailing to a letter-writing human in a community with a postal system." This, though, leaves unresolved the tension between the two views of affordances identified above: affordances as persisting, animal-independent resources versus affordances as organism-dependent relations that arise during the course of activities.

We suggest that this tension, at least, can be resolved by invoking the distinction between the habitat of a species and the umwelt of an individual organism. The affordance concept serves a different purpose depending on whether we invoke it in the habitat or in the umwelt. In the former case, affordances are dispositional properties, or persisting resources that exist across generations and exert evolutionary selection pressure. In the latter case they are relational properties that exist for only so long as a given animal continues to live, and that change as that animal develops new skills and abilities, or loses them. On the question of what affordances are, we thus agree with Fodor and Pylyshyn, who wrote, "Roughly, affordances are dispositional properties (because they concern what an organism could do with an object); and they are relational properties (because different organisms can do different things with objects of a given kind)" (1981, 144). Similarly, Reed (1996, p. 26) argues that an affordance becomes a relation only when a given animal uses it; until that point it is to be understood as a resource (i.e., a property of the habitat, in our terms). This resolution allows us to talk about inter-individual variation while avoiding a solipsistic view of perception in the individual (because the umwelt is still conceived as a lived perspective on a common habitat).

The two views of affordances are not in conflict with one another but are complementary. Indeed, the two views strengthen one another because affordances explain different things depending on whether they are invoked to explain behavior of the species (relative to a history in phylogeny) or of the individual (relative to a history in ontogeny).

\subsection{Information}

The second tension concerns the nature of ecological information. Ecological psychologists have traditionally asserted that information serves a dual role. First, it serves to convey structure from the environment to the animal. Second, it serves to guide the animal in its active exploration of that environment. Information points both ways: we must acknowledge that there is both information-about the environment, and information-for the animal (Michaels and Carello 1981, 37).

A slightly more technical version of this is encapsulated in what Chemero (2009, 111) refers to as the symmetry principle (see also Shaw and McIntyre 1974). On this formalization, information is conceived as the central term in a 1:1:1 relation that stands between structure in the world and structure in perception. This relation can be read from either end. Starting at the environment end, we can say that structure in the 
world specifies structure in energy arrays (patterns in sound, in light, etc.), which in turn specifies what an animal perceives. Starting from the animal end, we can say that the animal must explore energy arrays such that what it perceives specifies appropriate information that in turn specifies structure in the world that is adaptive for the animal's purposes. A thirsty animal must seek information that specifies water, for instance, while minimizing contact with information that specifies predators and other threats.

The tension here arises from the enactivist critique of Gibsonian information mentioned in Sect. 1. In addition to being a realist about affordances, Gibson was also a realist about information. He thought that all of the information about all of the affordances was in the environment, waiting for the right animal to show up and use it. And as we saw, Varela et al. (1991) accuse Gibsonians of being wholly concerned with information-about, and thus attempting "to build up the theory of perception almost entirely from the environment" (204). The worry here is that, if we are to say that there is information outside the organism that is 'about' structure in the world, this seems to invite an unwelcome return to Cartesian mind-body dualism. How can this external informational resource be incorporated into a mental process without invoking some sort of induction process for turning worldly, physical content into mental content?

For this reason, Hutto and Myin $(2017,86)$ assert that Gibsonian psychology "despite itself ... remains committed to the language, if not the framework, of information processing". They argue that a number of terms typically used by Gibsonians such as “" provision," "use," "gathering," and "pickup" of information "about" affordances ... are anathema to a nonrepresentational rendering of Gibson" (ibid.). In response to an earlier version of this critique, Van Dijk et al. (2015) go as far as to advocate that Gibsonians should abandon talk of information-about altogether, and restrict themselves only to talk of information-for; that is, we should think of information as something that does not exist until it is created through an animal's activities.

We prefer to avoid this strategy. We maintain that it is useful to think of information as something that exists, and can be described, relative to a potential animal, and not just relative to an actual, living animal that is already engaged in some activity. We suggest, instead, that the tension here can again be resolved by invoking the habitat/umwelt distinction. This resolution is summarized in Fig. 1. Information-about should be conceived as a property of the habitat. The habitat of bees contains flowers that emit pollen. The presence of the pollen is specified in chemical trails that diffuse in the air. These trails constitute information-about the presence of flowers. Indeed, a description of the habitat of the bee that leaves the existence of this information out of account would be an incomplete description. Meanwhile, information-for should be conceived as a property of the umwelt. When a given bee goes out looking for pollen, it is actively seeking patterns in energy that are adaptive to its purposes. Again, these two views are not in conflict. The bee is not seeking to transduce external content into internal content; it is actively exploring its umwelt, which is a subset of the speciesgeneral habitat. Information-about tells us what kinds of structure are available in abstract terms, for an ideal organism. Information-for tells us how that structure enters into the directed activity of a living animal. 
(a) World (habitat)
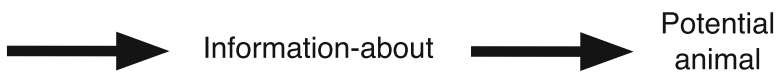

animal

(b)
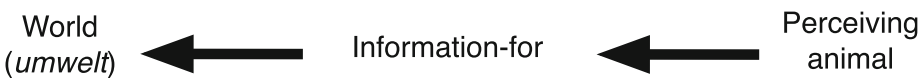

Fig. 1 The two-way nature of information

\section{Unifying radical embodied cognitive science}

We argued above that making the distinction between the habitat and the umwelt allows for a resolution of several tensions that are internal to the field of ecological psychology. In this section we will argue that the distinction can further be used to clarify disagreements between ecological psychologists and those working in neighboring disciplines. Specifically, it offers a way to make sense of the relationship between ecological psychology and enactivism. This is important because a potential unification of these two approaches promises perhaps the most complete alternative to cognitivism as a working metatheory for the study of minds (Chemero 2009; Hutto and Myin 2017; Gallagher 2017; Baggs 2018).

In short, the difference between the two approaches is summarized in the two parts of Fig. 1. Ecological psychologists begin their investigation at the environment end of the animal-environment relation, as depicted in 1(a); enactivists begin at the animal end, as in 1(b). The ecological approach begins with an account of environmental structure that is external to the animal, and uses this to explain how informational resources arise through which the animal can direct its activities at its surroundings. The enactivist approach, meanwhile, begins with an account of the internal organization of the animal and uses this to explain how the animal goes about adaptively making sense of its surroundings, in the process of which it brings forth its umwelt. Because these two approaches have different explanatory targets, they are not in conflict, but are complementary. Historically, however, the two approaches have maintained a cautious distance from one another. They have developed from different traditions and starting assumptions, so some work will be required if the two approaches are to be unified successfully.

An important area of apparent disagreement lies in the two approaches' stances towards realism. Ecological psychologists claim to be realists; enactivists typically align themselves with constructivism, which is an explicitly anti-realist position (Riegler 2005). This demands clarification. What do ecological psychologists mean when they say they are realists?

The first thing to note is that when Gibson himself used the word environment, he used it ambiguously, sometimes meaning habitat and sometimes meaning umwelt. The same is not true of Gibson's early followers. When Turvey et al. (1981) rigorously systematized Gibson's theory, they eliminated this ambiguity, and used the word 'environment' to mean what we have called the habitat. Because the overwhelming majority of ecological psychologists studied either with Turvey and Shaw at the University of Connecticut or with their former students, most work in ecological psy- 
chology has also taken the word 'environment' to refer to the habitat of a generic member of a species. Ecological realism, briefly, is the view that the habitat (not the umwelt) exists independently of a given animal, that it contains meaning, and that this is the appropriate scale at which to investigate human and animal behavior. Thus there is some justification to Varela et al's claim that ecological psychologists "build up the theory of perception almost entirely from the environment", while enactivists "build up the theory of perception from the structural coupling of the animal" (1991, 204; see above). The environment considered as the habitat does indeed leave out the history of structural coupling of individual animals. Our proposed distinction between the environment and the umwelt, however, brings it back in. It is the history of an individual's coupling to the environment - that she learned to read Japanese kanji, to play bass, to do tricks on a skateboard-that determines which of the affordances of the habitat are part of her umwelt. Because an umwelt is part of a habitat, which is part of the physical world, the concept enables ecological psychologists to account for the structural coupling of an individual animal, but maintain the kind of realism that Gibson argued for. However, the kind of realism that is maintained is not the kind that Varela et al rightly criticize. The umwelt of an individual organism is neither "pre-given" nor a mental construction; it is enacted during the individual's history of development and learning.

We have been careful to say that ecological psychologists can maintain the kind of realism they prefer, but have not said that we have presented a necessarily realist view. Whether this is a realist view depends upon where one starts in considering it. We have, so far, been starting with ontology. There is the physical world; when one considers it from the point of view an idealized member of a species, parts of it partly constitute a habitat; when one considers it from the point of view of an individual, parts of it partly constitute an umwelt. Those, like enactivists, who are inspired largely by phenomenology, would start epistemically. An individual experiences an umwelt; with some work, an individual can learn about a habitat and the physical world. We can put this, phenomenologically, by saying that only the umwelt is given in experience; knowledge of the world beyond the umwelt, of the habitat and physical world is theoretical or inferential. Husserl (1913/2012) argued that to do phenomenology properly, to attend to the experiences themselves, one has to bracket questions about the world beyond the experiences. The umwelt, of course, cannot be bracketed. This does not imply skepticism about the existence of the habitat or physical world, of course, but it gives the umwelt a special status. As far as we can tell all enactivists are committed to granting a special status to the given umwelt, and oppose the idea of perception as recovering a "pre-given" world. (See, e.g., Varela et al. 1991; Thompson 2007; Gallagher and Zahavi 2012; Di Paolo et al. 2017; Gallagher 2017.)

We noted above that the idealism v. realism debate is not useful, for our purposes. Where one stands on this debate is more a matter of temperament than philosophical argument. We do, however, acknowledge that the distinction we have drawn between habitat and umwelt can be used to support the enactivist (and phenomenologist) claim that access to the umwelt is privileged. Indeed, we agree that the umwelt is privileged in some sense: the umwelt has a first-person perspective; the umwelt is the set of affordances that are available to an individual animal, given the animal's biological make up, its development, its history of learning. Phenomenologists (and enactivists) 
describe this privilege by saying that the umwelt is given in experience; ecological psychologists (and enactivists) describe this privilege by saying that the umwelt is perceived directly. Enactivists tend to use the two terms interchangeably (e.g., Di Paolo et al. 2017). This makes sense since both 'given in experience' and 'perceived directly' imply that access to the umwelt is not mediated by representations or inferential processes. It is important to be clear that, despite the connotations of 'given', directly perceiving the umwelt typically takes work. As Gibson (1966) pointed out, the human visual system includes the eyes, brain, head, neck, torso, and legs, and direct visual perception requires moving. For example, seeing the tomato as a three-dimensional object, as having parts that do not reflect light to where you are sitting (Nöe 2004), requires eye movements and postural sway (Balasubramaniam et al. 2000; Chemero 2016; Faries and Chemero 2018). Similarly, haptically perceiving the sponginess of a sponge is no less direct because it takes time and requires the work of squeezing (O'Regan 2011). Indeed, that experiencing the umwelt requires work is built into the very name 'enactivism': an organism enacts its umwelt.

This whole discussion comes down to the following concern: how do we incorporate first-person experience into cognitive science without sliding into a solipsistic view of the mind? The concern is that we are each trapped inside our own umwelt: we perceive the world only in terms that are meaningful to us, and moreover we cannot even comprehend that there might be more to the world than what we have personally experienced.

Fortunately, solipsism is not inevitable. The way to avoid solipsism, for radical embodied cognitive scientists, is to adopt a historical-developmental perspective. At birth, we are not trapped in our umwelt. On the contrary, our umwelt comes to have the meaning it does only because it is shaped by the presence of other actors. This is well illustrated by Vygotsky's (1978) explanation of the genesis of the pointing gesture. He suggests that the universal infant practice of pointing at things that they want, but only their caregivers can reach, develops from the infant's trying and failing to reach those things with their own hands. That is, the infant who tries and fails to reach a desired toy has placed her hand in a position very similar to the one she will later use to point at it. Crucially, the failed reaching gesture metamorphoses into the pointing gesture only when it is interpreted as such by an adult. The adult interprets the reach as a point, and the adult gives the child the toy that it was reaching for. Over time, the child learns that instead of failing to reach for things with its own arms, it can successfully reach for things by recruiting other actors. The umwelt is expanded. To the extent that we are able to learn throughout our life, the umwelt never constitutes a limit on our experience, but is merely a label for the subset of our surroundings that we are currently oriented towards.

The umwelt is not something we are trapped in because we can always see beyond it to the next thing we can learn. If we were trapped inside the umwelt, then learning would be impossible. That humans perceive beyond their own umwelts, and do so directly, is compatible with something that enactivists have been pointing out for more than a decade now: that the human mind is deeply social and 'intersubjective' (e.g., Thompson 2007; De Jaegher and Di Paolo 2007; Froese and Gallagher 2012; Gallagher 2017). A consequence of this deep sociality is that we perceive the umwelt of other humans - that is, we are sensitive to the way the world appears to others, or we 
perceive the relation between other animals and their surroundings. Indeed, this seems to be an ability that goes beyond humans. The back door does not afford opening for a pet dog, but the dog can perceive that it does for humans.

If the umwelts of other animals are directly perceived, they are no less accessible than a perceiver's own umwelt. It might take work to directly perceive the affordances for another human, but it also takes work to perceive our own affordances. We can perceive that the Japanese newspaper affords reading for Satoshi, even though it does not for us. We can perceive that our cats can fit through the pet door, even though we are too big (we can perceive the umgebung of our pet, in von Uexküll's terms). The final question is whether this extends to the parts of the physical world that are not part of our umwelts, and that cannot be incorporated into our umwelt through learning to act on them. For some of the entities of modern science, it is possible to argue that we can only perceive them inferentially. There is a longstanding dispute in the philosophy of science concerning whether scientists are able to see through telescopes, statistical software, and the like in the same way that they see the surfaces around them through reflected light intercepted with their naked eyes (van Fraassen 1980; Hacking 1983). It is certainly arguable, perhaps convincingly, that even experts can perceive subatomic particles and other theoretical entities only indirectly. We don't wish to take a stance on this here. It is enough for us to have shown that, even if we start with the directly perceived umwelt, given (perhaps effortfully) in our experience, we are not trapped inside it. We can directly perceive beyond it, at least for a ways.

We hope that with our tri-partite distinction between three senses of environment we have set out a framework that makes sense of the relationship between ecological psychology and enactivism. If you are an ecological psychologist, you start from the objective, third-person point of view with the physical world. Gibson realized that most of the physical world is not part of the habitat of any animal, and as such it does not contain meaning. The habitat, which is a subset of the physical world considered as resources for animals with particular kinds of abilities, does contain meanings. An individual member of a species develops and learns and is enculturated and comes to have a portion of this habitat as its umwelt. The enactivist begins with the subjective, first-person point of view with the umwelt enacted by an individual person. Because people are social, they can directly perceive the umwelts enacted by other people. Because we learn, we can perceive beyond the things we currently know how to do to: we can perceive the world as a target of learning. The ecological account of external structure is compatible with the enactivist account of the internal organization of the animal. Life happens in the dialectical confrontation of the two. With this in place, perhaps we can move beyond talking about the need to reconcile ecological psychology and enactivism to actually beginning the hard work of developing scientific collaborations between these two varieties of radical embodied cognitive science.

Acknowledgements Edward Baggs was supported by funding from the European Union's Horizon 2020 research and innovation programme under grant agreement No 706432. Anthony Chemero was supported by the Charles Phelps Taft Research Center. 


\section{Compliance with ethical standards}

Conflict of interest The authors declare that they have no conflict of interest.

Open Access This article is distributed under the terms of the Creative Commons Attribution 4.0 International License (http://creativecommons.org/licenses/by/4.0/), which permits unrestricted use, distribution, and reproduction in any medium, provided you give appropriate credit to the original author(s) and the source, provide a link to the Creative Commons license, and indicate if changes were made.

\section{References}

Baggs, E. (2018). A psychology of the in between? Review of "Sensorimotor life: An enactive proposal" by Ezequiel Di Paolo, Thomas Buhrmann, and Xabier Barandiaran. Constructivist Foundations, 13(3), 395-397.

Baggs, E. \& Chemero, A. (to appear). The third sense of environment. In J. B. Wagman \& J. J. C. Blau (Eds.), Perception as information detection: Reflections on Gibson's ecological approach to visual perception. New York, NY: Taylor \& Francis [Preprint available at https://dx.doi.org/10.17605/OSF. IO/SXMRZ].

Balasubramaniam, R., Riley, M. A., \& Turvey, M. (2000). Specificity of postural sway to the demands of a precision task. Gait and Posture, 11(1), 12-24.

Chemero, A. (2003). An outline of a theory of affordances. Ecological Psychology, 15(2), 181-195.

Chemero, A. (2009). Radical embodied cognitive science. Cambridge, MA: MIT Press.

Chemero, A. (2016). Sensorimotor empathy. Journal of Consciousness Studies, 23(5-6), 138-152.

Costall, A. (1995). Socializing affordances. Theory and Psychology, 5(4), 467-481.

De Jaegher, H., \& Di Paolo, E. (2007). Participatory sense-making. Phenomenology and the Cognitive Sciences, 6(4), 485-507.

Di Paolo, E., Buhrmann, T., \& Barandiaran, X. (2017). Sensorimotor life: An enactive proposal. Oxford: Oxford University Press.

Faries, F., \& Chemero, A. (2018). Dynamic information processing. In M. Sprevak \& M. Colombo (Eds.), Routledge handbook of the computational mind (pp. 134-148). London: Routledge.

Fodor, J. A., \& Pylyshyn, Z. W. (1981). How direct is visual perception? Some reflections on Gibson's “ecological approach". Cognition, 9(2), 139-196.

Froese, T., \& Gallagher, S. (2012). Getting interaction theory (IT) together: Integrating developmental, phenomenological, enactive, and dynamical approaches to social interaction. Interaction Studies, 13(3), 436-468.

Gallagher, S. (2017). Enactivist interventions: Rethinking the mind. Oxford: Oxford University Press.

Gallagher, S., \& Zahavi, D. (2012). The phenomenological mind (2nd ed.). Abingdon: Routledge.

Gibson, J. J. (1966). The senses considered as perceptual systems. Boston: Houghton-Mifflin.

Gibson, J. J. (1967). Autobiography. In E. G. Boring \& G. Lindsay (Eds.), A history of psychology in autobiography (Vol. 5, pp. 125-143). New York, NY: Appleton-Century-Crofts.

Gibson, J. J. (1975). Events are perceivable but time is not. In J. T. Fraser \& N. Lawrence (Eds.), The study of time II. New York: Springer.

Gibson, J. J. (1979). The ecological approach to visual perception. Boston: Houghton-Mifflin.

Hacking, I. (1983). Representing and intervening. Cambridge: Cambridge University Press.

Heft, H. (2017). Perceptual information of "An entirely different order": The "cultural environment" in The senses considered as perceptual systems. Ecological Psychology, 29(2), 122-145.

Husserl, E. (1913/2012). Ideas. Trans. Dermot Moran. London: Routledge.

Hutto, D. D., \& Myin, E. (2017). Evolving enactivism: Basic minds meet content. Cambridge, MA: MIT Press.

Käufer, S., \& Chemero, A. (2015). Phenomenology: An introduction. Cambridge: Polity Press.

Maturana, H. R., \& Varela, F. J. (1987). The tree of knowledge: The biological roots of human understanding. New York: New Science Library/Shambhala Publications.

McGann, M. (2014). Enacting a social ecology: Radically embodied intersubjectivity. Frontiers in Psychology, $5,1321$. 
Mearleau-Ponty, M. (1942/1963). The structure of behavior. Trans. Alden Fisher. Pittsburgh: Duquesne University Press.

Merleau-Ponty, M. (1945/2012). Phenomenology of perception. Trans. Routledge: Donald Landes.

Michaels, C. F., \& Carello, C. (1981). Direct perception. Englewood Cliffs, NJ: Prentice-Hall.

Nöe, A. (2004). Action in perception. Cambridge, MA: MIT Press.

O'Regan, J. K. (2011). Why red doesn't sound like a bell: Understanding the feel of consciousness. Oxford: Oxford University Press.

O’Shea, J. R. (2018). Percepts and concepts. In A. Klein (Ed.), Oxford handbook to William James. Oxford: Oxford University Press.

Reed, E. S. (1988). James J. Gibson and the psychology of perception. New Haven, CT: Yale University Press.

Reed, E. S. (1996). Encountering the world: Toward an Ecological psychology. New York: Oxford University Press.

Riegler, A. (2005). The constructivist challenge. Constructivist Foundations, 1(1), 1-8.

Rietveld, E., \& Kiverstein, J. (2014). A rich landscape of affordances. Ecological Psychology, 26(4), 325-352.

Shaw, R., \& McIntyre, M. (1974). Algoristic foundations to cognitive psychology. In W. Weimer \& D. Palermo (Eds.), Cognition and symbolic processes. Hillsdale, NJ: Erlabaum.

Smith, B. C. (1988). The semantics of clocks. In J. H. Fetzer (Ed.), Aspects of artificial intelligence. Studies in cognitive systems (Vol. 1). Dordrecht: Springer.

Swenson, R. (1992). Autocatakinetics, yes-autopoiesis, no: Steps towards a unified theory of evolutionary ordering. International Journal of General Systems, 21(2), 207-228.

Swenson, R., \& Turvey, M. T. (1991). Thermodynamic reasons for perception-action cycles. Ecological Psychology, 3(4), 317-348.

Thompson, E. (2007). Mind in life. Cambridge, MA: Harvard University Press.

Turvey, M. T. (1992). Affordances and prospective control: An outline of the ontology. Ecological Psychology, 4(3), 173-187.

Turvey, M. T., Shaw, R. E., Reed, E. S., \& Mace, W. M. (1981). Ecological laws of perceiving and acting: In reply to Fodor and Pylyshyn (1981). Cognition, 9(3), 237-304.

Van Dijk, L., Withagen, R., \& Bongers, R. M. (2015). Information without content: A Gibsonian reply to enactivists' worries. Cognition, 134, 210-214.

Van Fraassen, B. C. (1980). The scientific image. Oxford: Oxford University Press.

Varela, F. J., Thompson, E., \& Rosch, E. (1991). The embodied mind: Cognitive science and human experience. Cambridge, MA: MIT Press.

Von Uexküll, J. (1934/1992). A stroll through the worlds of animals and men: a picture book of invisible worlds. Semiotica, 89(4):319-391.

Vygotsky, L. S. (1978). Mind in society: The development of higher psychological processes. Cambridge, MA: Harvard University Press.

Ward, D., Silverman, D., \& Villalobos, M. (2017). Introduction: The varieties of enactivism. Topoi, 36(3), $365-375$. 